\title{
Clinical review: intensive care unit acquired weakness
}

Greet Hermans ${ }^{1,2^{*}}$ and Greet Van den Berghe ${ }^{1,3}$

\begin{abstract}
A substantial number of patients admitted to the ICU because of an acute illness, complicated surgery, severe trauma, or burn injury will develop a de novo form of muscle weakness during the ICU stay that is referred to as "intensive care unit acquired weakness" (ICUAW). This ICUAW evoked by critical illness can be due to axonal neuropathy, primary myopathy, or both. Underlying pathophysiological mechanisms comprise microvascular, electrical, metabolic, and bioenergetic alterations, interacting in a complex way and culminating in loss of muscle strength and/or muscle atrophy. ICUAW is typically symmetrical and affects predominantly proximal limb muscles and respiratory muscles, whereas facial and ocular muscles are often spared. The main risk factors for ICUAW include high severity of illness upon admission, sepsis, multiple organ failure, prolonged immobilization, and hyperglycemia, and also older patients have a higher risk. The role of corticosteroids and neuromuscular blocking agents remains unclear. ICUAW is diagnosed in awake and cooperative patients by bedside manual testing of muscle strength and the severity is scored by the Medical Research Council sum score. In cases of atypical clinical presentation or evolution, additional electrophysiological testing may be required for differential diagnosis. The cornerstones of prevention are aggressive treatment of sepsis, early mobilization, preventing hyperglycemia with insulin, and avoiding the use parenteral nutrition during the first week of critical illness. Weak patients clearly have worse acute outcomes and consume more healthcare resources. Recovery usually occurs within weeks or months, although it may be incomplete with weakness persisting up to 2 years after ICU discharge. Prognosis appears compromised when the cause of ICUAW involves critical illness polyneuropathy, whereas isolated critical illness myopathy may have a better prognosis. In addition, ICUAW has shown to contribute to the risk of 1-year mortality. Future research should focus on new preventive and/or therapeutic strategies for this detrimental complication of critical illness and on clarifying how ICUAW contributes to poor longer-term prognosis.
\end{abstract}

\section{Introduction}

Generalized muscle weakness, which develops during the course of an ICU admission and for which no other cause can be identified besides the acute illness or its treatment, is labeled "intensive care unit acquired weakness" (ICUAW). ICUAW may affect peripheral as well as respiratory muscles. The "loss of flesh and strength" in patients with life-threatening infections was described in the nineteenth century [1]. However, it took another century before it was understood that ICUAW can be evoked either by critical illness polyneuropathy

\footnotetext{
*Correspondence: Greet.Hermans@uzleuven.be

${ }^{1}$ Laboratory of Intensive Care Medicine, Division of Cellular and Molecular

Medicine, KU Leuven, Herestraat 49, B-3000 Leuven, Belgium

${ }^{2}$ Medical Intensive Care Unit, Department of General Internal Medicine,

University Hospitals Leuven, Herestraat 49, B-3000 Leuven, Belgium

Full list of author information is available at the end of the article
}

(CIP) [2], by critical illness myopathy (CIM) [3], or by both [4] during the course of critical illness. ICUAW is a frequent complication of critical illness and is associated with a high morbidity and mortality of acute critical illnesses. In addition, recent data revealed that ICUAW may also have longer-term consequences, beyond the hospitalization phase. For example, ICUAW may be an important contributor to the post intensive care syndrome (PICS) [5]. This term includes the physical, mental, and cognitive dysfunctions that are part of the persisting disabilities, which extend beyond the acute hospitalization and have major impact on the quality of life of the growing population of ICU survivors.

This review aims to update the available knowledge regarding ICUAW, its clinical characteristics and diagnostic properties, the underlying mechanisms and predisposing factors, as well as its medical and socioeconomic 
consequences. In addition, possible avenues towards prevention and treatment of ICUAW will be reviewed.

\section{Incidence}

ICUAW is a frequent problem. The reported incidence varies depending on the patient population studied and on the timing of the evaluation. Weakness at awakening was found to be present in 26-65\% of patients who were mechanically ventilated for 5-7 days, respectively $[6,7]$, and $25 \%$ of these remained weak for at least another 7 days after awakening [8]. Among long-term ventilated patients ( $\geq 10$ days) ICUAW was diagnosed in up to $67 \%$ [9]. In another study $11 \%$ of patients treated in the ICU for at least 24 hours developed ICUAW [10], and when the ICU stay increased to 7-10 days ICUAW at awakening was present in $24-55 \%$ of patients [10-12]. In patients suffering from acute respiratory distress syndrome (ARDS), an ICUAW incidence of $60 \%$ has been reported at the time of awakening [13], and at hospital discharge this incidence was still $36 \%$ [14].

\section{Pathophysiology}

The mechanisms underlying ICUAW are complex and involve functional and structural alterations in both the muscles and the nerves.

In CIP, the pathological finding is axonal degeneration [15]. The pathogenesis of such axonal degeneration remains incompletely understood, in part explained by the invasiveness of nerve biopsies. Factors that play a role are microvascular changes in the endoneurium evoked by sepsis [16], which promotes vascular permeability and allows penetration of toxic factors into the nerve ends [17]. The endoneural edema resulting from increased permeability may impair energy delivery to the axon followed by axonal death. Direct toxic effects and mitochondrial dysfunction evoked by hyperglycemia may contribute to this process [18-20]. Animal experiments also identified channelopathy as a cause of rapidly occurring but reversible neuropathy [21]. Whether such a channelopathy also occurs in ICU patients, as a functional precursor of axonal degeneration that is found later in the course of critical illness, remains unclear [22].

In CIM, several factors are thought to play a role by negatively affecting muscle structure and function, all interacting in a complex manner [22]. A detailed overview of mediators and molecular mechanisms involved was published recently [23]. First, muscle atrophy can occur quite early during critical illness [24]. Muscle atrophy is brought about by increased breakdown and decreased synthesis of muscle protein [24, 25]. Several processes during critical illness may promote such wasting of muscle protein, which preferentially involves myosin $[25,26]$. These include inflammation, immobilization, the endocrine stress responses, the rapidly developing nutritional deficit, impaired microcirculation, and denervation [22, 27, 28]. Key proinflammatory mediators involved include tumor necrosis factor alpha, interleukin-1, and interleukin-6 [23]. Recently, another stress-induced cytokine, growth and differentiation factor-15 (GDF-15), a member of the transforming growth factor beta super family, was identified as a mediator of muscle atrophy during critical illness [29]. In addition to muscle atrophy, other factors may contribute to decreased muscle function. Muscle membrane inexcitability induced by sodium channel dysfunction is an early finding in CIM [30] and predicts the development of clinical muscle weakness [31]. An altered intracellular calcium homeostasis, affecting the excitation-contraction coupling, has also been shown to contribute to reduced contractility in animal sepsis models [32, 33]. The muscles of septic patients show signs of bioenergetic failure, comprising oxidative stress, mitochondrial dysfunction, and ATP depletion [34]. Finally, muscle atrophy and weakness are not synonymous [22]. Indeed, muscle quality might be even more important than muscle mass in determining muscle function and the development of ICUAW [35]. Autophagy, which is a cellular housekeeping system that mediates removal of damaged large organelles and protein aggregates, is an important factor in maintaining muscle fiber integrity [36], and deficient autophagy may have a crucial role in the development of ICUAW [35].

\section{Risk factors}

Several risk factors for the development of neuromuscular complications in the ICU have been reported. At the time when CIP was first described, sepsis, systemic inflammatory response syndrome (SIRS), and multiple organ failure (MOF) were considered to play a key role. Indeed, in the early case reports, sepsis was frequently present $[2,37]$. Hence, subsequent studies specifically focused on patients with sepsis and organ failure and reported a high incidence of neuromuscular complications [38-40]. ICUAW was therefore considered to be the peripheral component of a general neuromuscular organ failure evoked by sepsis, with septic encephalopathy being the central component. An independent role for sepsis [35], bacteremia [10, 41], SIRS [40, 42], and MOF [8] was subsequently suggested by several prospective studies. Indirectly, a role for sepsis and MOF in the development of neuromuscular complications of critical illness was further supported when other independent risk factors were identified, such as the use of vasopressors [41, 43] or aminoglycosides [10], certain mediators of inflammation [44], and the presence of septic encephalopathy [39]. The risk associated with a higher severity of illness, as reflected by the Acute Physiology and Chronic Health Evaluation score, was demonstrated in several studies [10, 35, 42, 45]. Hyperglycemia was also found to be an independent risk factor for electrophysiological 
[38] and clinical [10] signs of ICUAW, and increasing insulin dose reduced signs of ICUAW [46]. These data offer the potential to prevent ICUAW by controlling glycemia with insulin (see 'Prevention and therapy'). Providing early mobilization effectively reduced ICUAW [46], which is in line with the documented risk reduction in clinical or electrophysiological manifestations of ICUAW, associated with several indirect reflections of the duration of immobilization, such as duration of ICU stay $[38,43]$ and of mechanical ventilation prior to awakening [8], and the time until awakening and clinical assessment of muscle strength [35]. In one study, the duration of bed rest was the only factor consistently associated with weakness 3-24 months post ICU discharge [14]. This underscores the potential importance of treatments aiming to reduce the duration of immobilization in the ICU (see 'Prevention and therapy').

After a first case report of pronounced weakness in a patient treated with corticosteroids and neuromuscular blocking agents [47], multiple others followed. Denervated and steroid-treated animals showed muscle changes similar to those observed in critically ill patients [48]. Some prospective studies indeed suggested that corticosteroids $[8,35,45]$ and (prolonged) neuromuscular blocking agents $[18,35,39]$ may contribute to CIP/CIM or ICUAW. However, other prospective studies, of which some were randomized controlled trials, could not confirm such a role for corticosteroids $[10,13,14,18,39,40$, $42-44,46,49]$ or for neuromuscular blocking agents $[14,50]$. These apparently contradicting findings suggest that the relationship between these drugs and neuromuscular complications is more complex and depends on other factors such as dose, timing, and concomitant glycemic control [18]. Age was also identified as an independent risk factor for ICUAW $[35,46]$. This may to some extent reflect the importance of the premorbid physiological muscle reserve, although the actual premorbid functional status is determined by many other factors. The premorbid functional status is often difficult to document due to the unplanned nature of ICU admissions. One report identified parenteral nutrition as a risk factor for CIP [39]. The effect of nutritional strategies as a modifiable factor is further discussed in 'Prevention and therapy'. Other factors identified only in single studies might be incidental findings (female sex) [8] or related to other risk factors (hyperosmolality [39], hypoalbuminemia [38], renal replacement therapy [41]) and await confirmation.

Only few studies specifically addressed risk factors for respiratory weakness in the ICU. These studies demonstrated that respiratory muscle weakness is associated with infection or sepsis [51-53], disease severity [53], and peripheral weakness [51]. The phrenic nerve and diaphragm also show similar electrophysiologic abnormalities as the peripheral nerves and muscles [54], so these data suggest that respiratory weakness is indeed part of ICUAW [51, 53]. Additionally, the duration of mechanical ventilation may contribute to weakness $[55,56]$ and atrophy of the diaphragm $[56,57]$. This time-dependent and early development of diaphragmatic atrophy and dysfunction is also labeled "ventilator-induced diaphragmatic dysfunction" (VIDD) [58].

\section{Clinical signs}

ICUAW is characterized by symmetrical and flaccid weakness of the limbs, which is more pronounced in the proximal muscles than in the distal muscles $[8,59]$. Facial and ocular muscles are often spared [60]. Patients with ICUAW therefore typically respond to a painful stimulus with facial grimacing but with no or minimal withdrawal of the limbs. Tendon reflexes are generally reduced, although these can be normal. In the case of coexistent CIP, sensory symptoms may be present, including reduced or absent sensitivity to pain, temperature, and vibration. However, examination of the sensory function is generally difficult in critically ill patients.

When ICUAW is present, the respiratory muscles are often affected [51]. This contributes to delayed weaning from mechanical ventilation, which is often the clinical problem with which these patients present.

\section{Small fiber neuropathy and autonomic dysfunction: different entities or part of the spectrum of neuromuscular failure in critically ill patients? Small fiber neuropathy}

In addition to CIP, which is a length-dependent large fiber neuropathy, several small series of well-selected patients demonstrated the presence of nonlength-dependent small fiber neuropathy on skin biopsies taken in the acute phase of critical illness [61, 62]. This degeneration or loss of small fibers may be responsible for neuropathic pain, stocking and glove sensory loss, numbness, cool extremities, and burning pain in survivors of critical illness $[61,63]$. The available data indicate co-occurrence of small fiber neuropathy with CIP/CIM in a substantial number of cases, as well as a high incidence of sepsis or MOF in these patients. This suggests involvement of similar pathophysiological mechanisms [61]. Small fiber neuropathy, however, is also reported in patients without sepsis, MOF or CIP/CIM [61] and its pathophysiology has not yet been studied.

\section{Autonomic dysfunction}

Autonomic dysfunction, involving the peripheral and central sympathetic and parasympathetic systems, frequently occurs in critically ill patients [61, 64-66]. This dysfunction is documented by abnormal $\mathrm{R}-\mathrm{R}$ variation, the cold face test, denervation of skin sweat glands on biopsy, and 
the skin wrinkle test. Because autonomic dysfunction is reported in patients with CIP/CIM, with reduced intraepidermal nerve fiber density and septic encephalopathy, this again suggests a common pathway. Axonal degeneration of the sympathetic chain and vagal nerve was indeed documented on autopsy of patients with CIP [37]. Wieske et al. [64], however, did not find an association between abnormal heart rate variability, actually present in all studied patients, and ICUAW. Many confounders in the ICU affect heart rate variability and therefore this is possibly not the optimal indicator of autonomic dysfunction in this setting [64]. The impact of autonomic dysfunction on outcome also remains to be studied.

\section{Diagnosis}

\section{Clinical evaluation of muscle strength}

Current guidelines recommend a clinical diagnosis of ICUAW, made by bedside evaluation of the muscle strength with the use of the Medical Research Council (MRC) sum score [67]. This score appoints a value between 0 (no contraction at all) and 5 (normal muscle strength) for each of 12 muscle groups, including shoulder abduction, elbow flexion, wrist extension, hip flexion, knee extension, and dorsiflexion of the ankle, all scored bilaterally (Table 1 ). The sum score ranges between 0 and 60 , and ICUAW is diagnosed with a total $<48$ [8]. Additional electrophysiological examination for clinical purposes is only indicated when the clinical presentation or evolution is atypical or when focal deficit is present [67]. The MRC sum score has a number of limitations. It does not detect the cause of weakness and cannot differentiate between CIP and CIM. Also, patients need to be awake and fully cooperative; a subset of patients, ranging between $10 \%$ [13] and $75 \%$ [68], do not

Table 1 Medical Research Council sum score

\begin{tabular}{l} 
Muscle group evaluated \\
Wrist extension \\
Elbow flexion \\
Shoulder abduction \\
Dorsiflexion foot \\
Knee extension \\
Hip flexion \\
Appointed score \\
0, no visible/palpable contraction \\
1, visible/palpable contraction without movement of the limb \\
2, movement of the limb, but not against gravity \\
3, movement against gravity \\
4, movement against gravity and some resistance \\
5, normal \\
\hline
\end{tabular}

fulfill this criterion during their ICU stay. Reproducibility in critically ill patients was reported to be good $[6,59]$, but this was not confirmed by other studies $[68,69]$. Practical details of the scoring system concerning the adaptation of the original score for bedridden patients and use of rigorous criteria to define cooperation may be crucial to obtain reliable and reproducible results [70, 71]. The MRC sum score also has a ceiling effect and actual differentiation between 4 (subnormal strength) and 5 (normal strength) may be subjective [72].

Some other potentially interesting methods to evaluate the neuromuscular function include the use of handheld dynamometry and handgrip strength. Both are reproducible in the ICU [73]. Preliminary data suggest that handgrip strength relates to outcome [6] but these data need further confirmation. Muscle ultrasound allows detection of atrophy $[24,74]$ as well as architectural changes and fasciculation [75]. Ultrasound findings in the ICU setting, in contrast to other settings [76, 77], did not, however, correlate with muscle function or outcomes [75] in the few studies that are available. Preliminary data showed that reduced abductor polices strength following ulnar nerve stimulation in critically ill patients [78] but the relationship with global strength or outcome was not studied.

Respiratory muscle strength can be measured in the ICU using the maximal inspiratory pressure recorded following a volitional maneuver starting from the functional residual capacity [79]. This may be difficult, however, in ICU patients who are not cooperative. For such patients, a nonvolitional method using a one-way valve is a good alternative [80]. More sophisticated methods, such as measuring transdiaphragmatic pressure following magnetic phrenic nerve stimulation, is cumbersome and therefore not suited to daily practice [55].

\section{Electrophysiological testing}

Because of the shortcomings of the MRC sum score, the interest in alternative diagnostic tools remains. Full electrophysiological testing, including nerve conduction studies (NCS) and electromyography (EMG), is cumbersome, not readily available in many ICUs, time consuming, and costly. NCS typically reveal reduced compound muscle action potentials (CMAPs); in the case of (coexistent) CIP, sensory nerve action potentials (SNAPs) may be reduced, and nerve conduction velocity is normal or only slightly reduced [81]. In both CIP and CIM, spontaneous electrical activity may be present on EMG. SNAPs in critically ill patients may also be reduced due to edema. Voluntary muscle contraction, which requires a cooperative patient, or alternatively more complex electrophysiological methods such as direct muscle stimulation can be used to differentiate between CIP and CIM [31, 82]. Simplified electrophysiological screening using the peroneal nerve CMAP, potentially 
supplemented by the sural nerve amplitude, may be used to identify patients who require more extensive testing $[83,84]$. However, correlation between electrophysiological abnormalities and muscle weakness has not been studied in large patient populations; in particular, the importance of electrophysiological abnormalities in the absence of weakness is unclear.

\section{Biomarkers}

The use of biomarkers could allow better targeting of future novel therapies. Creatine kinase may be increased in patients with ICUAW but is not a good biomarker [8]. Plasma levels of neurofilaments, which are biomarkers of axonal injury, are also elevated in patients with ICUAW [85]. Peak neurofilament levels showed good discriminative power for weakness but this peak only occurred after patients were clinically evaluable and therefore did not allow early diagnosis [85]. Although no validated biomarkers are available currently, identification of new mediators involved in the development of ICUAW, such as GDF-15, may represent promising future candidates.

\section{Outcomes of ICUAW}

\section{Short-term implications}

ICUAW is associated with prolonged ICU and hospital stay, prolonged duration of mechanical ventilation, and increased ICU and hospital mortality [6-8, 10, 51, 86]. Several mechanisms may explain increased morbidity and mortality, including associated respiratory muscle weakness [51], pharyngeal dysfunction, and symptomatic aspiration [9]. The association between weakness and poor outcomes could indicate that ICUAW is either a marker or a mediator of poor outcome. A randomized interventional study, which is the state of the art for examining causality, is evidently not possible for weakness. Propensity score matching provides the closest alternative to explore a potential causal relationship [87]. This involves matching of weak patients to not-weak patients for all risk factors that could contribute both to weakness and to poor outcomes [11]. In such a matched population, the time to live weaning from mechanical ventilation and the time to live ICU and hospital discharge were significantly longer in weak patients, as compared with matched not-weak patients. Additionally, healthcare-related hospitalization costs were $30.5 \%$ higher. These data support a causal role between ICUAW and poor outcomes.

\section{Recovery from ICUAW and implications after the hospitalization phase}

Recovery from weakness typically occurs within weeks or months [88], but the most severe cases may not recover. A systematic review indicated that severe sequellae were present in $28 \%$ of patients [89]. Results from this thorough review were limited, however, by the lack of studies that included a large enough number of patients with sufficiently long follow-up. More recently, the proportion of patients with weakness was prospectively studied in patients with ARDS and showed a progressive decline over time from $36 \%$ at hospital discharge to $22 \%$ at 3 months, $7-15 \%$ at 6 months, $4-14 \%$ at 1 year and $9 \%$ at 2 years [14, 90]. These data support that the majority of patients recover within months, reaching a plateau at around 1 year. Not surprisingly, ICUAW independently predicted the discharge destination [11]. Increasing evidence from several small prospective studies pointed to worse prognosis of CIP than of CIM [91-94]. CIM might recover faster and more completely whereas (coexistent) CIP possibly impedes recovery.

The actual impact of ICUAW on physical function and health-related quality of life was first addressed in a landmark study of ARDS survivors showing that both were significantly impaired up to 5 years after ICU admission [95, 96]. As generalized weakness and fatigue were the dominant prevailing complaints in these survivors, ICUAW was considered to be a crucial factor explaining the findings [96]. Several other studies have confirmed such persisting physical limitations [97-101] as well as reduced quality of life following ARDS, sepsis, and mechanical ventilation [97, 98, 102], in addition to impaired return to work [92, 95, 96] and cognitive dysfunction [103]. ARDS survivors with weakness at any time during the 2-year follow-up had reduced physical function and health-related quality of life as compared with patients without weakness [97], although the independent contribution of ICUAW to these outcomes has not yet been studied. In contrast, weakness did independently contribute to 1-year mortality [11]. Additionally, the persistence and higher severity of weakness at ICU discharge further increased the risk of death within the first year [11].

Finally, although the number of patients with persisting weakness is small, there is a marked reduction in physical function in the majority of ARDS survivors [95]. This suggests that weakness is not the only culprit limiting physical function. Other potentially relevant factors in addition to muscle strength include proprioception, gait balance, spatial attention, cognitive function, mental health, central nervous dysfunction, pain, and entrapment neuropathy $[63,92,97,104]$.

\section{Prevention and therapy}

Aggressive treatment of sepsis is considered to be a cornerstone in the prevention of ICUAW. Although antiinflammatory therapies in sepsis in general have been disappointing and specific neuromuscular effects have not been studied, targeting newly discovered inflammatory mediators involved in muscle atrophy, such as GDF-15, may open new perspectives. Further preventive strategies include the reduction or avoidance of other known risk 
factors but only few randomized trials addressing these are available.

Insulin treatment aimed at normalizing glycemia as compared with tolerating hyperglycemia up to the renal threshold significantly reduced the incidence of electrophysiological signs of CIP/CIM and the need for prolonged mechanical ventilation in long-stay medical [18] and surgical [43] ICU patients. A subsequent multicenter trial [105] found increased mortality in patients treated to strict normoglycemia as compared with those receiving insulin to target somewhat higher blood glucose levels. Consequently, the optimal target for blood glucose remains a matter of debate and ongoing efforts are being made to more safely control glucose in the ICU [106].

Reducing the duration of immobilization is another potentially important target in the prevention of ICUAW. This target can be realized by decreasing the levels of sedation. Approaches aimed at sedating patients to the minimal level needed for comfort and safety clearly have overall beneficial effects [107]. The actual impact of such strategies on ICUAW has not been studied. Reducing the duration of immobilization with early physical therapy adjusted to the medical situation, muscle strength, and level of cooperation is another strategy that was shown to be safe and feasible in the ICU and improved outcome [108]. Additionally, quadriceps strength at hospital discharge improved in long-stay patients receiving passive or active exercise training using a bedside ergometer, as compared with patients receiving standard physiotherapy [109]. This training involved 20 minutes of bedcyling 5 days per week, from the 5th day following ICU admission. Both functional status and health-related quality of life at hospital discharge were also improved [109]. Early mobilization and occupational therapy within 72 hours of initiation of mechanical ventilation in addition to daily sedation interruption improved outcome, including functional status, although the incidence of ICUAW was not reduced [110]. The training consisted of an individually tailored daily program starting with passive range-ofmotion exercises in unresponsive patients, progressing to active range-of-motion exercises, bed mobility, sitting upright, transfer training, and eventually walking. A secondary analysis of this trial reported that, after correction of other risk factors, both early mobilization and increasing insulin dose independently prevented ICUAW [46]. Despite clear benefits from early mobilization of patients in the ICU, daily practice appears to vary significantly among centers and clinical settings $[111,112]$ and many barriers exist, hampering a wide implementation. Identification of subgroups of patients who are most likely to benefit would allow a better allocation of resources [113]. Patients with ICUAW might represent a group of particular interest but data supporting such an approach are currently lacking [114]. Analogous to the peripheral muscles, early mobilization of the diaphragm allowing for spontaneous breathing while avoiding overactivation is considered standard practice to minimize respiratory muscle weakness $[56,115]$.

A substantial number of ICU patients are not able to participate in active mobilization early. In this population, electrical muscle stimulation (EMS) could theoretically be used to activate and cultivate muscles during this phase. Several studies suggest potential beneficial effects of EMS in critically ill patients. The evidence remains inconclusive, however, because of equivocal results and several methodological issues $[116,117]$.

Finally, malnutrition was originally considered a major contributor to ICUAW and correction of the nutritional deficit using parenteral feeding appeared evident [2]. This paradigm was recently challenged by Puthacheary et al. [24], who reported that increased protein delivery during the first week in the ICU was associated with more pronounced muscle wasting. In addition, avoiding parenteral nutrition during the first week in the ICU, as compared with early supplementation of deficient enteral feeding, reduced the incidence of weakness and enhanced recovery thereof [35]. This beneficial effect was explained by enhanced autophagic quality control in the muscle fibers, whereas markers of atrophy remained unaffected. These findings suggest that the early catabolic phase during critical illness cannot be averted by artificial nutrition. Certain catabolic pathways, in particular autophagy, may be crucial to maintain muscle quality and function. Hence, targeting autophagy may be worthwhile to investigate further as a future treatment strategy. Also, early "trophic" feeding via the enteral route instead of full enteral feeding during the first week in the ICU did not have detrimental effects on physical function or strength measurements up to 1 year following ARDS [98].

\section{Conclusions}

ICUAW affects many critically ill patients and is associated with prolonged duration of mechanical ventilation, ICU stay, and hospital stay, as well as increased ICU and hospital mortality and healthcare-related hospitalization costs. In addition, following the acute phase of illness, ICUAW may be an important contributor to the physical limitations persisting in ICU survivors, associated with reduced health-related quality of life, as well as higher 1-year mortality. This underscores the importance for future research on prevention of ICUAW. In parallel, the underlying mechanisms contributing to the poor outcome of weak patients and the potential to avert unfavorable outcomes by post-ICU follow-up of these patients should also be investigated further. 


\section{Abbreviations}

ARDS: Acute respiratory distress syndrome; CIM: Critical illness myopathy; CIP: Critical illness polyneuropathy; CMAP: Compound muscle action potential; EMG: Electromyography; EMS: Electrical muscle stimulation; GDF-15: Growth and differentiation factor-15; ICUAW: Intensive care unit acquired weakness; MOF: Multiple organ failure; MRC: Medical Research Council; NCS: Nerve conduction studies; PICS: Post intensive care syndrome; SIRS: Systemic inflammatory response syndrome; SNAP: Sensory nerve action potential; VIDD: Ventilator-induced diaphragmatic dysfunction.

\section{Competing interests}

The authors declare that they have no competing interests.

\section{Acknowledgements}

This work was supported by the Research Foundation-Flanders (FWO), Belgium (G.0399.12, G.0592.12). GH received a Postdoctoral Fellowship from the Clinical Research Fund (KOF) of the University Hospitals Leuven, Belgium. $\mathrm{GVdB}$, via the University of Leuven, receives structural research financing via the Methusalem program, funded by the Flemish Government (METH08/07), and holds an ERC Advanced grant (AdvG-2012-321670) from the Ideas Program of the EU FP7.

\section{Author details}

'Laboratory of Intensive Care Medicine, Division of Cellular and Molecular Medicine, KU Leuven, Herestraat 49, B-3000 Leuven, Belgium. ${ }^{2}$ Medical Intensive Care Unit, Department of General Internal Medicine, University Hospitals Leuven, Herestraat 49, B-3000 Leuven, Belgium. ${ }^{3}$ Department of Intensive Care Medicine, University Hospitals Leuven, Herestraat 49, B-3000 Leuven, Belgium.

\section{Published online: 05 August 2015}

\section{References}

1. Osler W. Principles and practice of medicine. New York: Appleton D; 1892.

2. Bolton CF, Gilbert JJ, Hahn AF, Sibbald WJ. Polyneuropathy in critically ill patients. J Neurol Neurosurg Psychiatry. 1984;47:1223-31.

3. Zochodne DW, Bolton CF, Thompson RT, Driedger AA, Hahn AF, Gilbert JJ. Myopathy in critical illness. Muscle Nerve. 1986;9:652.

4. Bednarik J, Lukas Z, Vondracek P. Critical illness polyneuromyopathy: the electrophysiological components of a complex entity. Intensive Care Med. 2003;29:1505-14

5. Needham DM, Davidson J, Cohen H, Hopkins RO, Weinert C, Wunsch $H$, et al. Improving long-term outcomes after discharge from intensive care unit: report from a stakeholders' conference. Crit Care Med. 2012;40:502-9.

6. Ali NA, O'Brien Jr JM, Hoffmann SP, Phillips G, Garland A, Finley JC, et al. Acquired weakness, handgrip strength, and mortality in critically ill patients. Am J Respir Crit Care Med. 2008:178:261-8.

7. Sharshar T, Bastuji-Garin S, Stevens RD, Durand MC, Malissin I, Rodriguez P, et al. Presence and severity of intensive care unit-acquired paresis at time of awakening are associated with increased intensive care unit and hospital mortality. Crit Care Med. 2009;37:3047-53.

8. De Jonghe B, Sharshar T, Lefaucheur JP, Authier FJ, Durand-Zaleski I, Boussarsar $M$, et al. Paresis acquired in the intensive care unit: a prospective multicenter study. JAMA. 2002;288:2859-67.

9. Mirzakhani H, Williams JN, Mello J, Joseph S, Meyer MJ, Waak K, et al. Muscle weakness predicts pharyngeal dysfunction and symptomatic aspiration in long-term ventilated patients. Anesthesiology. 2013;119:389-97.

10. Nanas S, Kritikos K, Angelopoulos E, Siafaka A, Tsikriki S, Poriazi M, et al. Predisposing factors for critical illness polyneuromyopathy in a multidisciplinary intensive care unit. Acta Neurol Scand. 2008;118:175-81.

11. Hermans G, Van Mechelen H, Clerckx B, Vanhullebusch T, Mesotten D, Wilmer A, et al. Acute outcomes and 1-year mortality of ICU-acquired weakness: a cohort study and propensity matched analysis. Am J Respir Crit Care Med. 2014;190:410-20.

12. Tzanis G, Vasileiadis I, Zervakis D, Karatzanos E, Dimopoulos S, Pitsolis T, et al. Maximum inspiratory pressure, a surrogate parameter for the assessment of ICU-acquired weakness. BMC Anesthesiol. 2011;11:14.

13. Bercker S, Weber-Carstens S, Deja M, Grimm C, Wolf S, Behse F, et al. Critical illness polyneuropathy and myopathy in patients with acute respiratory distress syndrome. Crit Care Med. 2005;33:711-5.
14. Fan E, Dowdy DW, Colantuoni E, Mendez-Tellez PA, Sevransky JE, Shanholtz C, et al. Physical complications in acute lung injury survivors: a 2-year longitudinal prospective study. Crit Care Med. 2013;42:849-59.

15. Latronico N, Fenzi F, Recupero D, Guarneri B, Tomelleri G, Tonin P, et al. Critical illness myopathy and neuropathy. Lancet. 1996;347:1579-82.

16. Fenzi F, Latronico N, Refatti N, Rizzuto N. Enhanced expression of E-selectin on the vascular endothelium of peripheral nerve in critically ill patients with neuromuscular disorders. Acta Neuropathol (Berl). 2003;106:75-82.

17. Bolton CF. Neuromuscular manifestations of critical illness. Muscle Nerve. 2005:32:140-63.

18. Hermans G, Wilmer A, Meersseman W, Milants I, Wouters PJ, Bobbaers H, et al. Impact of intensive insulin therapy on neuromuscular complications and ventilator-dependency in MICU. Am J Respir Crit Care Med. 2007;175:480-9.

19. Vanhorebeek I, De Vos R, Mesotten D, Wouters PJ, Wolf-Peeters C, Van den Berghe G. Protection of hepatocyte mitochondrial ultrastructure and function by strict blood glucose control with insulin in critically ill patients. Lancet. 2005;365:53-9.

20. Van den Berghe G. How does blood glucose control with insulin save lives in intensive care? J Clin Invest. 2004;114:1187-95.

21. Novak KR, Nardelli P, Cope TC, Filatov G, Glass JD, Khan J, et al. Inactivation of sodium channels underlies reversible neuropathy during critical illness in rats. J Clin Invest. 2009;119:1150-8.

22. Batt J, Dos Santos CC, Cameron Jl, Herridge MS. Intensive care unit-acquired weakness: clinical phenotypes and molecular mechanisms. Am J Respir Crit Care Med. 2013;187:238-46

23. Friedrich OR, Van den Berghe G, Van Horebeek I, Hermans G, Rich MM, Larsson L. The sick and the weak: neuropathies/myopathies in the critically ill_cellular mechanisms of complex disease entities in the ICU. Physiol Rev. 2015, in press.

24. Puthucheary ZA, Rawal J, McPhail M, Connolly B, Ratnayake G, Chan P, et al. Acute skeletal muscle wasting in critical illness. JAMA. 2013;310:1591-600.

25. Derde S, Hermans G, Derese I, Guiza F, Hedstrom Y, Wouters PJ, et al. Muscle atrophy and preferential loss of myosin in prolonged critically ill patients. Crit Care Med. 2012:40:79-89.

26. Wollersheim T, Woehlecke J, Krebs M, Hamati J, Lodka D, Luther-Schroeder A, et al. Dynamics of myosin degradation in intensive care unit-acquired weakness during severe critical illness. Intensive Care Med. 2014;40:528-38.

27. Bloch S, Polkey MI, Griffiths M, Kemp P. Molecular mechanisms of intensive care unit acquired weakness. Eur Respir J. 2012;39:1000-11.

28. Weber-Carstens S, Schneider J, Wollersheim T, Assmann A, Bierbrauer J Marg A, et al. Critical illness myopathy and GLUT4: significance of insulin and muscle contraction. Am J Respir Crit Care Med. 2013;187:387-96.

29. Bloch SA, Lee JY, Syburra T, Rosendahl U, Griffiths MJ, Kemp PR, et al. Increased expression of GDF-15 may mediate ICU-acquired weakness by down-regulating muscle microRNAs. Thorax. 2015;70:219-28.

30. Ackermann KA, Bostock H, Brander L, Schroder R, Djafarzadeh S, Tuchscherer $D$, et al. Early changes of muscle membrane properties in porcine faecal peritonitis. Crit Care. 2014;18:484.

31. Weber-Carstens S, Koch S, Spuler S, Spies CD, Bubser F, Wernecke KD, et al, Nonexcitable muscle membrane predicts intensive care unit-acquired paresis in mechanically ventilated, sedated patients. Crit Care Med. 2009;37:2632-7.

32. Rossignol B, Gueret G, Pennec JP, Morel J, Rannou F, Giroux-Metges MA et al. Effects of chronic sepsis on contractile properties of fast twitch muscle in an experimental model of critical illness neuromyopathy in the rat. Crit Care Med. 2008;36:1855-63.

33. Zink W, Kaess M, Hofer S, Plachky J, Zausig YA, Sinner B, et al. Alterations in intracellular Ca2+-homeostasis of skeletal muscle fibers during sepsis. Crit Care Med. 2008:36:1559-63.

34. Brealey D, Brand M, Hargreaves I, Heales S, Land J, Smolenski R, et al. Association between mitochondrial dysfunction and severity and outcome of septic shock. Lancet. 2002;360:219-23.

35. Hermans G, Casaer MP, Clerckx B, Guiza F, Vanhullebusch T, Derde S, et al. Effect of tolerating macronutrient deficit on the development of intensive-care unit acquired weakness: a subanalysis of the EPaNIC trial. Lancet Respir Med. 2013;1:621-9.

36. Masiero E, Agatea L, Mammucari C, Blaauw B, Loro E, Komatsu M, et al. Autophagy is required to maintain muscle mass. Cell Metab. 2009;10:507-15.

37. Zochodne DW, Bolton CF, Wells GA, Gilbert JJ, Hahn AF, Brown JD, et al. Critical illness polyneuropathy. A complication of sepsis and multiple organ failure. Brain. 1987;110(Pt 4):819-41. 
38. Witt NJ, Zochodne DW, Bolton CF, Grand'Maison F, Wells G, Young GB, et al. Peripheral nerve function in sepsis and multiple organ failure. Chest. 1991;99:176-84.

39. Garnacho-Montero J, Madrazo-Osuna J, Garcia-Garmendia JL, Ortiz-Leyba C, Jimenez-Jimenez FJ, Barrero-Almodovar A, et al. Critical illness polyneuropathy: risk factors and clinical consequences. A cohort study in septic patients. Intensive Care Med. 2001;27:1288-96.

40. Bednarik J, Vondracek P, Dusek L, Moravcova E, Cundrle I. Risk factors for critical illness polyneuromyopathy. J Neurol. 2005;252:343-51.

41. Van den Berghe G, Wouters P, Weekers F, Verwaest C, Bruyninckx F, Schetz $M$, et al. Intensive insulin therapy in the critically ill patients. N Engl J Med. 2001;345:1359-67.

42. de Letter MA, Schmitz PI, Visser LH, Verheul FA, Schellens RL, Op de Coul DA, et al. Risk factors for the development of polyneuropathy and myopathy in critically ill patients. Crit Care Med. 2001;29:2281-6.

43. Van den Berghe G, Schoonheydt K, Becx P, Bruyninckx F, Wouters PJ. Insulin therapy protects the central and peripheral nervous system of intensive care patients. Neurology. 2005;64:1348-53.

44. Weber-Carstens S, Deja M, Koch S, Spranger J, Bubser F, Wernecke KD, et al. Risk factors in critical illness myopathy during the early course of critical illness: a prospective observational study. Crit Care. 2010;14:R119.

45. Campellone JV, Lacomis D, Kramer DJ, Van Cott AC, Giuliani MJ. Acute myopathy after liver transplantation. Neurology. 1998;50:46-53.

46. Patel BK, Pohlman AS, Hall JB, Kress JP. Impact of early mobilization on glycemic control and ICU-acquired weakness in critically ill patients who are mechanically ventilated. Chest. 2014;146:583-9.

47. MacFarlane IA, Rosenthal FD. Severe myopathy after status asthmaticus. Lancet. 1977;2:615

48. Massa R, Carpenter S, Holland P, Karpati G. Loss and renewal of thick myofilaments in glucocorticoid-treated rat soleus after denervation and reinnervation. Muscle Nerve. 1992;15:1290-8.

49. Steinberg KP, Hudson LD, Goodman RB, Hough CL, Lanken PN, Hyzy R, et al. Efficacy and safety of corticosteroids for persistent acute respiratory distress syndrome. N Engl J Med. 2006;354:1671-84.

50. Papazian L, Forel JM, Gacouin A, Penot-Ragon C, Perrin G, Loundou A, et al. Neuromuscular blockers in early acute respiratory distress syndrome. N Engl J Med. 2010;363:1107-16.

51. De Jonghe B, Bastuji-Garin S, Durand MC, Malissin I, Rodrigues P, Cerf C, et al. Respiratory weakness is associated with limb weakness and delayed weaning in critical illness. Crit Care Med. 2007;35:2007-15.

52. Supinski GS, Callahan LA. Diaphragm weakness in mechanically ventilated critically ill patients. Crit Care. 2013;17:R120.

53. Demoule A, Jung B, Prodanovic H, Molinari N, Chanques G, Coirault C, et al. Diaphragm dysfunction on admission to the intensive care unit. Prevalence, risk factors, and prognostic impact-a prospective study. Am J Respir Crit Care Med. 2013;188:213-19.

54. Zifko UA, Zipko HT, Bolton CF. Clinical and electrophysiological findings in critical illness polyneuropathy. J Neurol Sci. 1998;159:186-93.

55. Hermans G, Agten A, Testelmans D, Decramer M, Gayan-Ramirez G. Increased duration of mechanical ventilation is associated with decreased diaphragmatic force: a prospective observational study. Crit Care. 2010;14:R127.

56. Jaber S, Petrof BJ, Jung B, Chanques G, Berthet JP, Rabuel C, et al. Rapidly progressive diaphragmatic weakness and injury during mechanical ventilation in humans. Am J Respir Crit Care Med. 2011;183:364-71.

57. Levine S, Nguyen T, Taylor N, Friscia ME, Budak MT, Rothenberg P, et al. Rapid disuse atrophy of diaphragm fibers in mechanically ventilated humans. N Engl J Med. 2008;358:1327-35.

58. Jaber S, Jung B, Matecki S, Petrof BJ. Clinical review: ventilator-induced diaphragmatic dysfunction-human studies confirm animal model findings! Crit Care. 2011;15:206.

59. Hermans G, Clerckx B, Vanhullebusch T, Segers J, Vanpee G, Robbeets C, et al. Interobserver agreement of medical research council sum-score and handgrip strength in the intensive care unit. Muscle Nerve. 2012;45:18-25.

60. Bolton CF, Laverty DA, Brown JD, Witt NJ, Hahn AF, Sibbald WJ. Critically ill polyneuropathy: electrophysiological studies and differentiation from Guillain-Barre syndrome. J Neurol Neurosurg Psychiatry. 1986;49:563-73.

61. Latronico N, Filosto M, Fagoni N, Gheza L, Guarneri B, Todeschini A, et al. Small nerve fiber pathology in critical illness. PLoS One. 2013;8, e75696.

62. Skorna M, Kopacik R, Vlckova E, Adamova B, Kostalova M, Bednarik J. Small nerve fiber pathology in critical illness documented by serial skin biopsies. Muscle Nerve. 2014. doi:10.1002/mus.24489.
63. Angel MJ, Bril V, Shannon P, Herridge MS. Neuromuscular function in survivors of the acute respiratory distress syndrome. Can J Neurol Sci. 2007;34:427-32.

64. Wieske L, Chan Pin Yin DR, Verhamme C, Schultz MJ, van Schaik IN, Horn J. Autonomic dysfunction in ICU-acquired weakness: a prospective observational pilot study. Intensive Care Med. 2013;39:1610-7.

65. Wieske L, Kiszer ER, Schultz MJ, Verhamme C, van Schaik IN, Horn J. Examination of cardiovascular and peripheral autonomic function in the ICU: a pilot study. J Neurol. 2013;260:1511-7.

66. Bolton C, Thompson J, Bernardi L, Voll C, Young B. The cardiac R-R variation and sympathetic skin response in the intensive care unit. Can J Neurol Sci. 2007;34:313-15.

67. Kress JP, Hall JB. ICU-acquired weakness and recovery from critical illness. N Engl J Med. 2014;370:1626-35.

68. Hough CL, Lieu BK, Caldwell ES. Manual muscle strength testing of critically ill patients: feasibility and interobserver agreement. Crit Care. 2011;15:R43.

69. Connolly BA, Jones GD, Curtis AA, Murphy PB, Douiri A, Hopkinson NS, et al. Clinical predictive value of manual muscle strength testing during critical illness: an observational cohort study. Crit Care. 2013;17:R229.

70. Hermans G, Gosselink R. Should we abandon manual muscle strength testing in the ICU? Crit Care. 2011;15:127.

71. Vanpee G, Hermans G, Segers J, Gosselink R. Assessment of limb muscle strength in critically ill patients: a systematic review. Crit Care Med. 2014:42:701-11.

72. Hermans G, Clerckx B, Vanhullebusch T, Segers J, Vanpee G, Robbeets C, et al. Interobserver agreement of Medical Research Council sum-score and handgrip strength in the intensive care unit. Muscle Nerve. 2012;45:18-25.

73. Vanpee $G$, Segers J, Van Mechelen H, Wouters P, Van den Berghe G, Hermans $G$, et al. The interobserver agreement of handheld dynamometry for muscle strength assessment in critically ill patients. Crit Care Med. 2011;39:1929-34.

74. Gruther W, Benesch T, Zorn C, Paternostro-Sluga T, Quittan M, Fialka-Moser $V$, et al. Muscle wasting in intensive care patients: ultrasound observation of the M. quadriceps femoris muscle layer. J Rehabil Med. 2008;40:185-9.

75. Grimm A, Teschner U, Porzelius C, Ludewig K, Zielske J, Witte OW, et al. Muscle ultrasound for early assessment of critical illness neuromyopathy in severe sepsis. Crit Care. 2013;17:R227.

76. Freilich RJ, Kirsner RL, Byrne E. Isometric strength and thickness relationships in human quadriceps muscle. Neuromuscul Disord. 1995;5:415-22.

77. Chi-Fishman G, Hicks JE, Cintas HM, Sonies BC, Gerber LH. Ultrasound imaging distinguishes between normal and weak muscle. Arch Phys Med Rehabil. 2004:85:980-6.

78. Eikermann M, Koch G, Gerwig M, Ochterbeck C, Beiderlinden M, Koeppen S, et al. Muscle force and fatigue in patients with sepsis and multiorgan failure. Intensive Care Med. 2006;32:251-9.

79. ATS/ERS Statement on respiratory muscle testing. Am J Respir Crit Care Med. 2002;166:518-624

80. Truwit JD, Marini JJ. Validation of a technique to assess maximal inspiratory pressure in poorly cooperative patients. Chest. 1992;102:1216-9.

81. Latronico N, Bolton CF. Critical illness polyneuropathy and myopathy: a major cause of muscle weakness and paralysis. Lancet Neurol. 2011;10:931-41.

82. Lefaucheur JP, Nordine T, Rodriguez P, Brochard L. Origin of ICU acquired paresis determined by direct muscle stimulation. J Neurol Neurosurg Psychiatry. 2006;77:500-6.

83. GiVITI Study Investigators, Latronico N, Nattino G, Guarneri B, Fagoni N, Amantini $A$, et al. Validation of the peroneal nerve test to diagnose critical illness polyneuropathy and myopathy in the intensive care unit: the multicentre Italian CRIMYNE-2 diagnostic accuracy study. F1000Research. 2014;3:127.

84. Moss M, Yang M, Macht M, Sottile P, Gray L, McNulty M, et al. Screening for critical illness polyneuromyopathy with single nerve conduction studies. Intensive Care Med. 2014;40:683-90.

85. Wieske L, Witteveen E, Petzold A, Verhamme C, Schultz MJ, van Schaik IN, et al. Neurofilaments as a plasma biomarker for ICU-acquired weakness: an observational pilot study. Crit Care. 2014;18:R18.

86. De Jonghe B, Bastuji-Garin S, Sharshar T, Outin H, Brochard L. Does ICU-acquired paresis lengthen weaning from mechanical ventilation? Intensive Care Med. 2004:30:1117-21.

87. Martens EP, Pestman WR, de BA, Belitser SV, Klungel OH. Systematic differences in treatment effect estimates between propensity score methods and logistic regression. Int J Epidemiol. 2008;37:1142-7. 
88. Bolton CF, Breuer AC. Critical illness polyneuropathy. Muscle Nerve. 1999;22:419-24.

89. Latronico N, Shehu I, Seghelini E. Neuromuscular sequelae of critical illness Curr Opin Crit Care. 2005;11:381-90.

90. Needham DM, Dinglas VD, Morris PE, Jackson JC, Hough CL, Mendez-Tellez PA, et al. Physical and cognitive performance of patients with acute lung injury 1 year after initial trophic versus full enteral feeding. EDEN trial follow-up. Am J Respir Crit Care Med. 2013;188:567-76.

91. Intiso D, Amoruso L, Zarrelli M, Pazienza L, Basciani M, Grimaldi G, et al. Long-term functional outcome and health status of patients with critical illness polyneuromyopathy. Acta Neurol Scand. 2011;123:211-9.

92. Koch S, Wollersheim T, Bierbrauer J, Haas K, Morgeli R, Deja M, et al. Long-term recovery in critical illness myopathy is complete, contrary to polyneuropathy. Muscle Nerve. 2014;50:431-6.

93. Guarneri B, Bertolini G, Latronico N. Long-term outcome in patients with critical illness myopathy or neuropathy: the Italian multicentre CRIMYNE study. J Neurol Neurosurg Psychiatry. 2008;79:838-41.

94. Koch S, Spuler S, Deja M, Bierbrauer J, Dimroth A, Behse F, et al. Critical illness myopathy is frequent: accompanying neuropathy protracts ICU discharge. J Neurol Neurosurg Psychiatry. 2011;82:287-93.

95. Herridge MS, Tansey CM, Matte A, Tomlinson G, az-Granados N, Cooper A, et al. Functional disability 5 years after acute respiratory distress syndrome. N Engl J Med. 2011;364:1293-304.

96. Herridge MS, Cheung AM, Tansey CM, Matte-Martyn A, Diaz-Granados N, Al Saidi $F$, et al. One-year outcomes in survivors of the acute respiratory distress syndrome. N Engl J Med. 2003;348:683-93.

97. Fan E, Dowdy DW, Colantuoni E, Mendez-Tellez PA, Sevransky JE, Shanholtz C, et al. Physical complications in acute lung injury survivors: a two-year longitudinal prospective study. Crit Care Med. 2014;42:849-59.

98. Needham DM, Dinglas VD, Bienvenu OJ, Colantuoni E, Wozniak AW, Rice TW, et al. One year outcomes in patients with acute lung injury randomised to initial trophic or full enteral feeding: prospective follow-up of EDEN randomised trial. BMJ. 2013;346:f1532.

99. Bienvenu OJ, Colantuoni E, Mendez-Tellez PA, Dinglas VD, Shanholtz C, Husain N, et al. Depressive symptoms and impaired physical function after acute lung injury: a 2-year longitudinal study. Am J Respir Crit Care Med. 2012;185:517-24.

100. Iwashyna TJ, Ely EW, Smith DM, Langa KM. Long-term cognitive impairment and functional disability among survivors of severe sepsis. JAMA. 2010;304:1787-94.

101. Barnato AE, Albert SM, Angus DC, Lave JR, Degenholtz HB. Disability among elderly survivors of mechanical ventilation. Am J Respir Crit Care Med. 2011;183:1037-42.

102. Hopkins RO, Weaver LK, Collingridge D, Parkinson RB, Chan KJ, Orme Jr JF. Two-year cognitive, emotional, and quality-of-life outcomes in acute respiratory distress syndrome. Am J Respir Crit Care Med. 2005;171:340-7.

103. Pandharipande PP, Girard TD, Ely EW. Long-term cognitive impairment after critical illness. N Engl J Med. 2014;370:185-6.

104. Herridge MS, Batt J, Santos CD. ICU-acquired weakness, morbidity, and death. Am J Respir Crit Care Med. 2014;190:360-2.

105. Finfer S, Chittock DR, Su SY, Blair D, Foster D, Dhingra V, et al. Intensive versus conventional glucose control in critically ill patients. N Engl J Med. 2009:360:1283-97.

106. Wernerman J, Desaive T, Finfer S, Foubert L, Furnary A, Holzinger U, et al. Continuous glucose control in the ICU: report of a 2013 round table meeting. Crit Care. 2014;18:226.

107. Reade MC, Finfer S. Sedation and delirium in intensive care. N Engl J Med. 2014;370:1567.

108. Morris PE, Goad A, Thompson C, Taylor K, Harry B, Passmore L, et al. Early intensive care unit mobility therapy in the treatment of acute respiratory failure. Crit Care Med. 2008;36:2238-43.

109. Burtin C, Clerckx B, Robbeets C, Ferdinande P, Langer D, Troosters T, et al. Early exercise in critically ill patients enhances short-term functional recovery. Crit Care Med. 2009:37:2499-505.

110. Schweickert WD, Pohlman MC, Pohlman AS, Nigos C, Pawlik AJ,

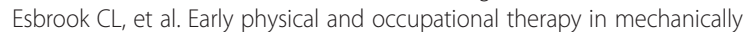
ventilated, critically ill patients: a randomised controlled trial. Lancet. 2009;373:1874-82.
111. The TEAM. Study investigators, Hodgson C, Bellomo R, Berney S, Bailey M, Buhr H, Denehy L, Harrold M, Higgins A, Presneill J, Saxena M, Skinner E, Young P, Webb S. Early mobilization and recovery in mechanically ventilated patients in the ICU: a bi-national, multi-centre, prospective cohort study. Crit Care. 2015;19:81

112. Hodgin KE, Nordon-Craft A, McFann KK, Mealer ML, Moss M. Physical therapy utilization in intensive care units: results from a national survey. Crit Care Med. 2009;37:561-6. quiz 566-8.

113. Fan E, Cheek F, Chlan L, Gosselink R, Hart N, Herridge MS, et al. An official American Thoracic Society Clinical Practice guideline: the diagnosis of intensive care unit-acquired weakness in adults. Am J Respir Crit Care Med. 2014;190:1437-46.

114. Mehrholz J, Pohl M, Kugler J, Burridge J, Muckel S, Elsner B. Physical rehabilitation for critical illness myopathy and neuropathy. Cochrane Database Syst Rev. 2015;3, CD010942.

115. Eikermann M, Latronico N. What is new in prevention of muscle weakness in critically ill patients? Intensive Care Med. 2013;39:2200-3.

116. Hermans $G$, De Jonghe B, Bruyninckx F, Van den Berghe $G$. Interventions for preventing critical illness polyneuropathy and critical illness myopathy. Cochrane Database Syst Rev. 2014;1, CD006832.

117. Maffiuletti NA, Roig M, Karatzanos E, Nanas S. Neuromuscular electrical stimulation for preventing skeletal-muscle weakness and wasting in critically ill patients: a systematic review. BMC Med. 2013;11:137. 